\title{
Transplanting Hybrid Potato Seedlings at Increased Densities Enhances Tuber Yield and Shifts Tuber-Size Distributions
}

\author{
Luuk C. M. van Dijk ${ }^{1,2}$. Michiel E. de Vries ${ }^{2}$. \\ Willemien J. M. Lommen ${ }^{1}$ D Paul C. Struik ${ }^{1}$ D
}

Received: 31 March 2021 / Accepted: 12 August 2021 / Published online: 19 October 2021 (c) The Author(s) 2021

\begin{abstract}
To contribute to the development of a novel cropping system for potato grown from greenhouse-derived seedlings from hybrid true potato seeds, planting density trials were carried out under normal Dutch agronomic conditions. For two consecutive years, 5-week-old seedlings of two experimental genotypes were transplanted into farmers' potato production fields at two contrasting locations: a flat-bed system on sandy soil and a traditional ridge system on clay soil. Planting densities were 6.25 , $12.5,25,50,100$ and 200 plants $/ \mathrm{m}^{2}$ in the flat-bed system, and 3.125, 4.688, 6.25, $12.5,25$ and 50 plants $/ \mathrm{m}^{2}$ in the ridge system. In general, increasing planting density of hybrid seedlings per area decreased tuber fresh weight per plant and reduced the number of tubers per plant. On a per hectare basis, an increased planting density resulted in increased total tuber yield and number of tubers up to very high densities, but finally both parameters levelled off. Highest total tuber yields harvested were 107 and $45 \mathrm{Mg} / \mathrm{ha}$ for the flat-bed and ridge system, respectively. On flat-beds, the optimal planting density for total yield was 50 plants $/ \mathrm{m}^{2}$. On ridges, planting density interacted with year and genotype, resulting in an optimum planting density of 25 plants $/ \mathrm{m}^{2}$ to reach the maximum total yield. Obtained yields in the commercial size classes Baby Baker $(20<$ size class $\leq 35 \mathrm{~mm})$ and Seed Tubers $(28<$ size class $\leq 50 \mathrm{~mm}$ ) were in general very high on the flat-beds, with a maximum Seed Tuber yield of $64 \mathrm{Mg} / \mathrm{ha}$ at 50 plants $/ \mathrm{m}^{2}$. The current study showed that transplanted hybrid seedlings are feasible alternatives for seed-tuber-grown systems for certain potato outlets.
\end{abstract}

Keywords Hybrid diploid potato $\cdot$ Nursery $\cdot$ Plant density $\cdot$ Seedling tubers $\cdot$ True potato seed $\cdot$ Tuber-size distribution

Luuk C. M. van Dijk

luuk.vandijk@wur.nl

Extended author information available on the last page of the article 


\section{Introduction}

Diploid hybrid breeding in potato (Solanum tuberosum L.) is a promising new technology that facilitates rapid introduction of favourable traits in new varieties (Jansky et al. 2016; Bonierbale et al. 2020; Ghislain and Douches 2020). The technology results in diploid hybrid true potato seeds (TPS). The use of hybrid TPS will require novel cultivation systems to produce ware or seed tubers (Lindhout et al. 2018). Depending on variety, region and crop management, field-sown hybrid TPS and transplanted hybrid seedlings could potentially be used in these new cultivation systems. These may then produce either seed tubers or ware tubers (Almekinders et al. 1996; Lindhout et al. 2018; van Dijk et al. 2021).

In potato, adaptive crop management, involving the choice of variety, soil tillage, nutrient application and especially plant density, is a tool to steer tuber sizes to their specific target size required for different commercial outlets (Struik et al. 1990; Blauer et al. 2013). For seed-tuber-grown crops, the stem number per unit area is the most suitable measure for density (Reestman and De Wit 1959; Wurr 1974; Allen 1978). High stem densities usually result in fewer and smaller tubers per stem than low stem densities (Reestman and De Wit 1959; Allen 1978; Wiersema 1989). Per unit area, total tuber yield and total number of tubers increase with increasing plant density, but at the cost of the number and size of large-sized tubers; therefore, plant density can be optimised for specific potato market segments. In contrast to plants grown from seed tubers, TPS seedlings only form one main stem and do not produce below-ground basal stem branches. Therefore, stolons and tubers only develop from the main stem (Kacheyo et al. 2021); this makes plant density equal to stem density. Plant density will therefore be an important factor in TPS-grown crops to manipulate number of tubers and tuber-size distribution.

The effects of planting density on number of tubers, size distribution and yield of potato crops grown from transplanted seedlings or directly sown TPS are little studied (Wiersema 1984; Çalişkan et al. 2009), and not yet for diploid hybrid genotypes grown under Dutch agronomic conditions. This study focuses on planting density effects of transplanted seedlings of diploid potato hybrids. Recently, van Dijk et al. (2021) reported that transplanted hybrid seedlings produce total tuber yields of $32 \mathrm{Mg} / \mathrm{ha}$, with c. 12 tubers per plant, when cultivated in a conventional Dutch ridge system $(66,667$ plants/ha). However, it is unknown (1) what a suitable planting density is to transplant diploid hybrid seedlings in the field; and (2) how planting density of these transplanted seedlings affects yield, number and size distribution of progeny tubers.

The aim of this study was to establish under Dutch agronomic conditions the effect of planting density on yield, number and size distribution of tubers and to explore optimum planting densities for different potato production markets. Therefore, field trials on planting density effects were carried out in 2 years with two genotypes under common Dutch potato cultivation practices at two locations: a clay soil on which a traditional $75-\mathrm{cm}$ ridge system was used, and a sandy soil on which a flat-bed system was used. 
This study was part of the Potarei project whose purpose is to explore scenarios for novel and improved cultivation pathways for potatoes based on diploid hybrid true potato seeds, using experimental hybrid genotypes to gain first insights. The project aims to lay the foundation for further research in potato cultivation pathways for hybrid potato. Therefore, this study will elaborate on additional studies on specific aspects which are important to develop a practical-working cultivation system for transplanted hybrid potato seedlings.

\section{Materials and Methods}

\section{Hybrid Potato Genotypes and Greenhouse Nursery}

Seedlings of two experimental diploid hybrids, H03 and H04, were raised by the Dutch potato breeding company Solynta in 2017 and 2018 during a 5-week greenhouse nursery period, which included a hardening-off phase. Both experimental hybrids originated from the breeding programme described by Lindhout et al. (2018) and were derived from similar research lines as the hybrids studied by Stockem et al. (2020). Hybrid true seeds were sown by hand in 104-plug nursery trays on 13 April in 2017 and on 3 April in 2018 and cultivated as described by van Dijk et al. (2021). Five weeks after sowing, 1 day prior to transplanting, a selection of transplantable seedlings (measuring 7-12 cm above-ground, containing 5-8 true leaves, BBCH stage 105-108; Kacheyo et al. 2021) was made consistent with the protocol of van Dijk et al. (2021), after which seedlings were irrigated and loaded for transport to the field locations.

\section{Field Locations, Experimental Design and Cultural Practices}

Field trials were conducted in commercial potato production fields at two locations: on a light sandy soil in Hilvarenbeek and a heavy clay soil in Est (see Stockem et al. (2020) for more specific details on soil types). In Hilvarenbeek, trials were both years embedded in potato fields with commercial varieties grown for a French fries processing plant. Due to the very light soil type, the grower in Hilvarenbeek cultivated all fields on flat, non-hilled, planting beds. Ridges would erode away during the growing season. In Est, trials were both years embedded in and surrounded by potato production fields with conventional ridges and with both French fries and table varieties for the fresh market. Therefore, the cultivation method was determined by soil texture at both locations. In both locations, the experiments were laid out in a randomised complete block design with four replicated blocks (Table 1) in which all of the combinations of genotype and density were randomised.

Seedlings were hand-transplanted in 2017 on 18 and 19 May in Hilvarenbeek and Est, respectively, and in 2018 on 8 and 7 May in Hilvarenbeek and Est, respectively. In Hilvarenbeek, seedlings were planted in the planting bed using a square planting pattern, which allowed for higher planting densities compared with the traditional ridges as used in Est (see Table 2). In Est, seedlings were planted in a type of double-row system, on conventional potato ridges of $75 \mathrm{~cm}$. Seedlings were not planted straight in the centre of the ridge, but alternatingly transplanted c. $3 \mathrm{~cm}$ left and right 
Table 1 Experimental details; all experiments were laid out in four blocks

\begin{tabular}{|c|c|c|c|c|c|}
\hline \multirow[t]{2}{*}{ Location $^{\mathrm{a}}$} & \multirow[t]{2}{*}{ Year } & \multirow[t]{2}{*}{ Planting density (plants $/ \mathrm{m}^{2}$ ) } & \multirow[t]{2}{*}{ Genotype } & \multicolumn{2}{|l|}{ Date of: } \\
\hline & & & & Planting & Harvest \\
\hline \multicolumn{6}{|l|}{ Hilvarenbeek } \\
\hline $\begin{array}{r}\left(51^{\circ} 48^{\prime} 95^{\prime \prime} \mathrm{N},\right. \\
\left.5^{\circ} 09^{\prime} 27^{\prime \prime} \mathrm{E}\right)\end{array}$ & 2017 & $6.25,12.5,25,50,100,200$ & H03, H04 & 18 May & 25 October \\
\hline \multicolumn{6}{|l|}{ Hilvarenbeek } \\
\hline $\begin{array}{r}\left(51^{\circ} 49^{\prime} 23^{\prime \prime} \mathrm{N},\right. \\
\left.5^{\circ} 08^{\prime} 02^{\prime \prime} \mathrm{E}\right)\end{array}$ & 2018 & $6.25,12.5,25,50,100,200$ & H03, H04 & 8 May & 18 October \\
\hline \multicolumn{6}{|l|}{ Est } \\
\hline $\begin{array}{r}\left(51^{\circ} 84^{\prime} 73^{\prime \prime} \mathrm{N},\right. \\
\left.5^{\circ} 34^{\prime} 14^{\prime \prime} \mathrm{E}\right)\end{array}$ & 2017 & $3.125,4.688,6.25,12.5,25,50$ & H03, H04 & 19 May & 28 September \\
\hline \multicolumn{6}{|l|}{ Est } \\
\hline $\begin{array}{r}\left(51^{\circ} 84^{\prime} 92^{\prime \prime} \mathrm{N},\right. \\
\left.5^{\circ} 33^{\prime} 12^{\prime \prime} \mathrm{E}\right)\end{array}$ & 2018 & $3.125,4.688,6.25,12.5,25,50$ & $\mathrm{H} 03, \mathrm{H} 04$ & 7 May & 14 September \\
\hline
\end{tabular}

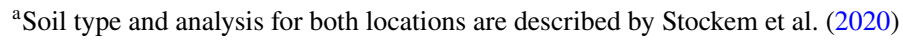

from the centre of the ridge, to ensure that seedlings at the highest planting densities would also fit on the ridge (Fig. S3). The main treatment of interest, Density, made it impossible to harvest equal numbers of plants from an equal area. Hence, Densities determined the exact net and gross-plot dimensions, (Table 2) but the plot dimension itself was not part of the experimental treatment factors (Table 1). Minimum requirements for plot dimensions were set to harvest at least an area of $0.8 \mathrm{~m}^{2}$ (especially for high planting densities) which contained at least 10 transplanted seedlings (especially for low planting densities) (see Table 2). All net-plot data were recalculated to a per ha or per plant basis.

At both locations in both years, seedlings were irrigated twice after transplanting to stimulate fast re-growth after transplanting. Two weeks after transplanting, additional irrigation was applied to avoid water-limiting conditions, following the growers' practices as applied to their commercial crops. Also, nutrient and cropprotection applications were done according to the practice of the respective growers. Haulm killing took place about 2-3 weeks prior to harvest at both locations in both years. Due to differences in local climate and management, harvesting dates were different between the two locations, following the local growers' practices. In 2017, tubers were harvested at 160 days after transplanting (DAT) in Hilvarenbeek and 132 DAT in Est. In 2018, harvest took place 163 DAT in Hilvarenbeek and 130 DAT in Est. Tubers were hand-lifted and collected per net plot.

\section{Observations, Measurements and Calculations}

Two nearby weather stations were used to record temperature and precipitation on a daily base (Fig. 1). Weather station Gilze-Rijen is located at $13.5 \mathrm{~km}$ northwest from the experimental site in Hilvarenbeek (Fig. 1a-b) and weather station Herwijnen is located $13.5 \mathrm{~km}$ west from the experimental location Est (Fig. 1c-d). For both 


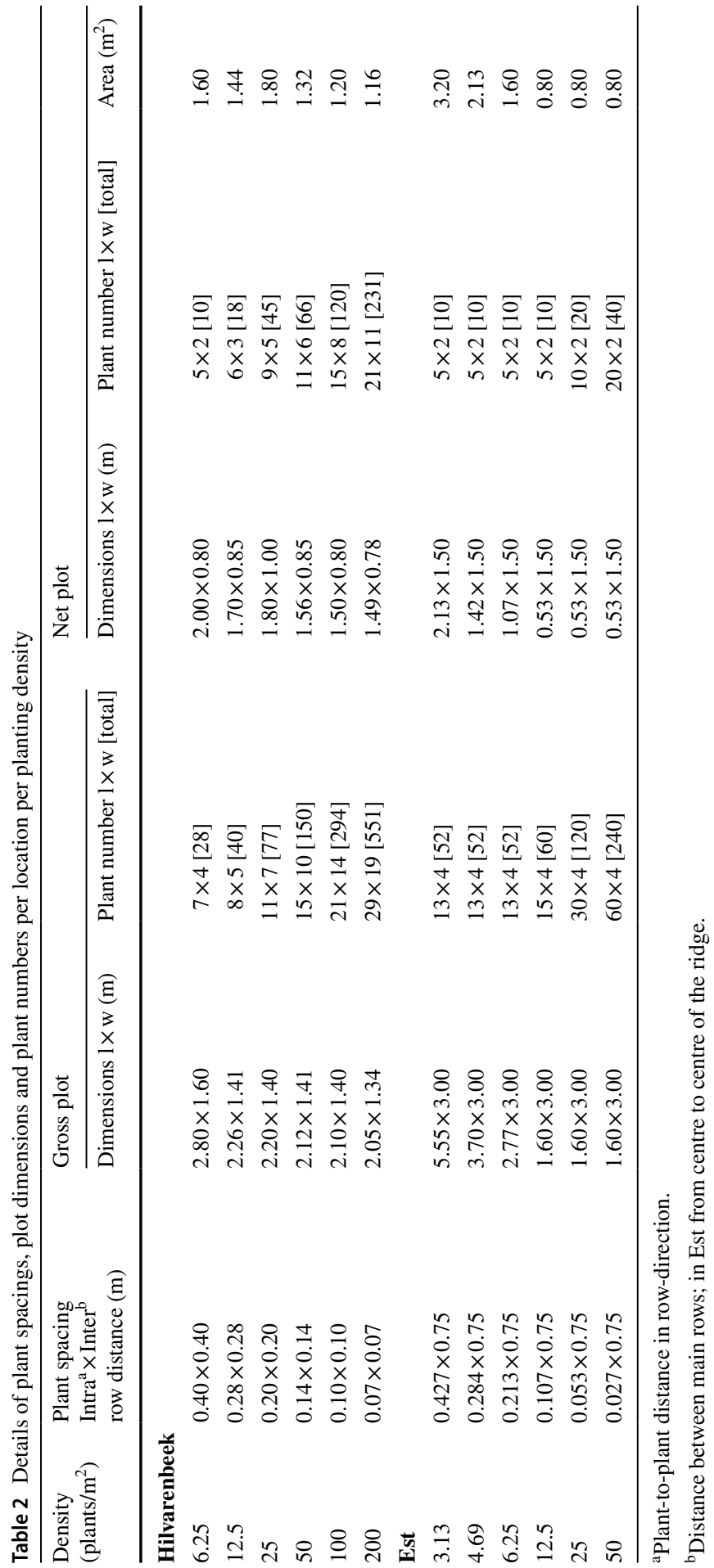



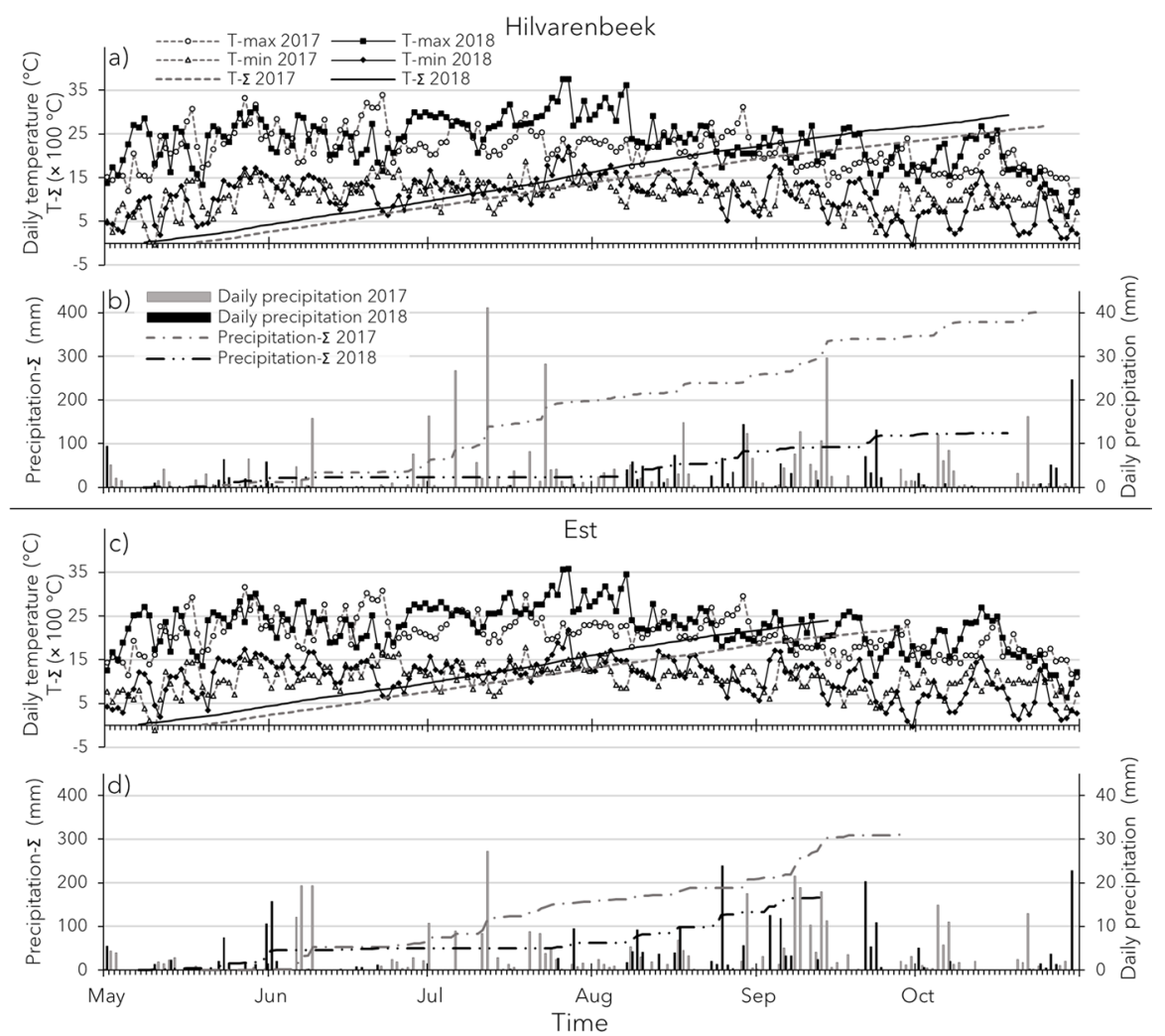

Fig. 1 Daily weather conditions for experimental years 2017 and 2018. Panels a-b include data from weather station Gilze-Rijen (13.5 km NW from trials Hilvarenbeek). Panels c-d include data from weather station Herwijnen (13.5 km W from trials Est). Daily minimum (T-min), maximum (T-max) and temperature sum $\left(\mathrm{T}-\Sigma\right.$ in ${ }^{\circ} \mathrm{Cd}, \mathrm{T}$-base $\left.=0{ }^{\circ} \mathrm{C}\right)$ are in panels a and c. Daily precipitation and precipitation sum $(\Sigma)$ are in panels $\mathbf{b}$ and $\mathbf{d}$. The length of the T- $\Sigma$ and precipitation- $\Sigma$ curves corresponds with the field period of every individual trial

locations, season 2017 received more precipitation compared with 2018, while 2018 resulted in a higher temperature sum compared with 2017.

After harvest, a tuber-phenotyping line was used to process the net-plot tuber samples in an automated manner. First, samples were cleaned from remaining soil and dirt; this step removed also tubers $<20 \mathrm{~mm}$. Then, the samples passed by a 3D-camera to assess individual tuber size and tuber volume, needed to calculate tuber number and fresh weight $(\mathrm{FW})$ per size class of all tubers in a net plot based on the total net-plot tuber FW, which was measured at the end of the phenotyping line (van Dijk et al. 2021; Stockem et al. 2020). Six basic tuber-size classes (sc) were used: $20<\mathrm{sc} \leq 28 \mathrm{~mm}, 28<\mathrm{sc} \leq 35 \mathrm{~mm}, 35<\mathrm{sc} \leq 50 \mathrm{~mm}, 50<\mathrm{sc} \leq 60 \mathrm{~mm}$, $60<\mathrm{sc} \leq 70 \mathrm{~mm}$ and $\mathrm{sc}>70 \mathrm{~mm}$. Data per hectare were calculated from the obtained data per net plot. To be able to assess the planting density effect on production for different potato markets, three size classes were defined: Baby Bakers $(20<\mathrm{sc} \leq 35 \mathrm{~mm})$, Seed Tubers $(28<\mathrm{sc} \leq 50 \mathrm{~mm})$ and Large Tubers $(\mathrm{sc}>50 \mathrm{~mm})$. 


\section{Statistical Analysis}

The programme GenStat 19th edition (VSN International Ltd. 2019) was used for statistical analyses. Since the Density treatments between the two Locations were unbalanced, first an analysis of total tuber FW and tuber number per ha over all factors was done by residual (restricted) maximum likelihood (REML). Location, Year, Density, Genotype and their interactions were set as fixed factors in the REML analysis.

Next, for each Location, a general analysis of variance was used to test whether there were significant main effects and interactions of Year, Density and Genotype. Fisher's protected LSD test $(\alpha=0.05)$ was used to compare means of factors or interactions which were significant $(P<0.05)$.

\section{Results}

\section{Overall Analysis}

First, an overall REML analysis was carried out to evaluate specifically the effects of Location on the results. The REML analysis showed that various significant twoway interactions and one four-way interaction occurred between Location, Density, Genotype and Year $(L \times D \times G \times Y)$ for total tuber fresh weight $(\mathrm{FW})$ and number of tubers per plant and per ha, but no three-way interactions (Table 3 ). The number of tubers produced per plant showed an $L \times D \times G \times Y$ interaction. For the other main parameters, $L \times D$ and $L \times G$ interactions were observed. No $L \times Y$ interactions were observed showing Location effects were stable across Years. Because of the many significant interactions, it was decided to carry out further ANOVA analyses per Location. This also better fitted the unbalanced planting densities across locations (Tables 1 and 2), and the different planting systems used at the different Locations (Table 2).

\section{Effects of Planting Density in Hilvarenbeek}

In Hilvarenbeek, in both Years, experiments were carried out on light sandy soil. Plants were transplanted in a square planting pattern in a flat-bed system using 6.25, $12.5,25,50,100$ and 200 plants $/ \mathrm{m}^{2}$ (Tables 1 and 2).

\section{Tuber Weight per Plant and Number of Tubers per Plant}

For FW and number of tubers $(>20 \mathrm{~mm})$ per plant, the Density $\times$ Year $(D \times Y)$ interaction was significant (Table 4). In both years, tuber FW per plant decreased with an increasing planting density (Fig. 2b; Table S1). In 2018, the differences in tuber FW between the higher planting densities were relatively smaller than in 2017 , and across all Densities, tuber weights per plant were lower in 2018 than in 2017. Tuber FW per plant decreased from 0.737 (at 6.25 plants $/ \mathrm{m}^{2}$ ) to $0.043 \mathrm{~kg}$ (at 200 plants/ 
Table 3 Results of the overall analyses by REML for total tuber fresh weight and numbers of tubers per plant and per ha. Significant $P$ values $(<\mathbf{0 . 0 1})$ are in bold

\begin{tabular}{|c|c|c|c|c|}
\hline \multirow[t]{2}{*}{ Fixed terms } & \multicolumn{2}{|l|}{ Data per plant } & \multicolumn{2}{|l|}{ Data per ha } \\
\hline & Tuber FW (kg/plant) & Tuber no. per plant & Total FW (Mg/ha) & Total tuber no. (\#/ha) \\
\hline Location (L) & 0.982 & 0.647 & 0.007 & 0.007 \\
\hline Density (D) & $<0.001$ & $<0.001$ & $<0.001$ & $<0.001$ \\
\hline Genotype (G) & 0.002 & $<0.001$ & $<0.001$ & 0.100 \\
\hline Year $(Y)$ & 0.141 & 0.165 & 0.137 & 0.070 \\
\hline $\mathrm{L} \times \mathrm{D}$ & $<0.001$ & $<0.001$ & $<0.001$ & $<0.001$ \\
\hline $\mathrm{L} \times \mathrm{G}$ & $<0.001$ & $<0.001$ & $<0.001$ & $<0.001$ \\
\hline $\mathrm{L} \times \mathrm{Y}$ & 0.957 & 0.711 & 0.485 & 0.421 \\
\hline $\mathrm{D} \times \mathrm{G}$ & 0.106 & $<0.001$ & 0.006 & $<0.001$ \\
\hline $\mathrm{D} \times \mathrm{Y}$ & $<0.001$ & $<0.001$ & 0.044 & $<0.001$ \\
\hline $\mathrm{G} \times \mathrm{Y}$ & 0.932 & $<0.001$ & 0.455 & $<0.001$ \\
\hline $\mathrm{L} \times \mathrm{D} \times \mathrm{G}$ & 0.027 & 0.410 & 0.024 & 0.724 \\
\hline $\mathrm{L} \times \mathrm{D} \times \mathrm{Y}$ & 0.123 & 0.097 & 0.206 & 0.011 \\
\hline $\mathrm{L} \times \mathrm{G} \times \mathrm{Y}$ & 0.385 & 0.435 & 0.058 & 0.978 \\
\hline $\mathrm{D} \times \mathrm{G} \times \mathrm{Y}$ & 0.901 & 0.313 & 0.368 & 0.198 \\
\hline $\mathrm{L} \times \mathrm{D} \times \mathrm{G} \times \mathrm{Y}$ & 0.129 & 0.007 & 0.039 & 0.015 \\
\hline
\end{tabular}

$\mathrm{m}^{2}$ ) in 2017 and from 0.473 to $0.028 \mathrm{~kg}$ in 2018. Also, the number of tubers per plant decreased with increasing planting density in both Years (Fig. 2h; Table S2).

Increasing the tuber-size class threshold from $>20$ ( $=$ total tuber FW and number per plant) to $>28,>35,>50$ and $>60 \mathrm{~mm}$ resulted in various Density $\times$ Genotype $(D \times G)$ and Density $\times$ Year $(D \times Y)$ interactions and one Density $\times$ Genotype $\times$ Year $(D \times G \times Y)$ interaction (Table 4). In all cases, tuber FW and number of tubers per plant decreased with increasing planting density (Fig. 2a-1; Tables S1 and S2). Between consecutive densities, the relative decrease in tuber weight was in general stronger than the relative decrease in number of tubers per plant. Higher overall weights and numbers per plant were found in 2017 vs 2018 and in H03 vs H04 (Tables S1 and S2).

\section{Total Yield and Total Number of Tubers per Hectare}

The $D \times G$ interaction was significant for total $(>20 \mathrm{~mm})$ tuber yield per ha (Table 4). Nevertheless, in both Genotypes, yield per ha increased with an increase in planting density from 6.25 to 50 plants $/ \mathrm{m}^{2}$ and the highest total tuber yields were achieved at planting densities between 50 and 200 plants $/ \mathrm{m}^{2}$ (Fig. 2m; Table S3). At these density ranges, total tuber yields were between $76-84 \mathrm{Mg} / \mathrm{ha}$ for genotype $\mathrm{H} 03$ and $53-61 \mathrm{Mg} / \mathrm{ha}$ for $\mathrm{H} 04$.

Total number of tubers $(>20 \mathrm{~mm})$ per ha showed significant $D \times G$ and $D \times Y$ interactions (Table 4). For all combinations, total number of tubers per ha increased with an increase in planting density (Fig. 2s-t; Table S4). This increase was not 


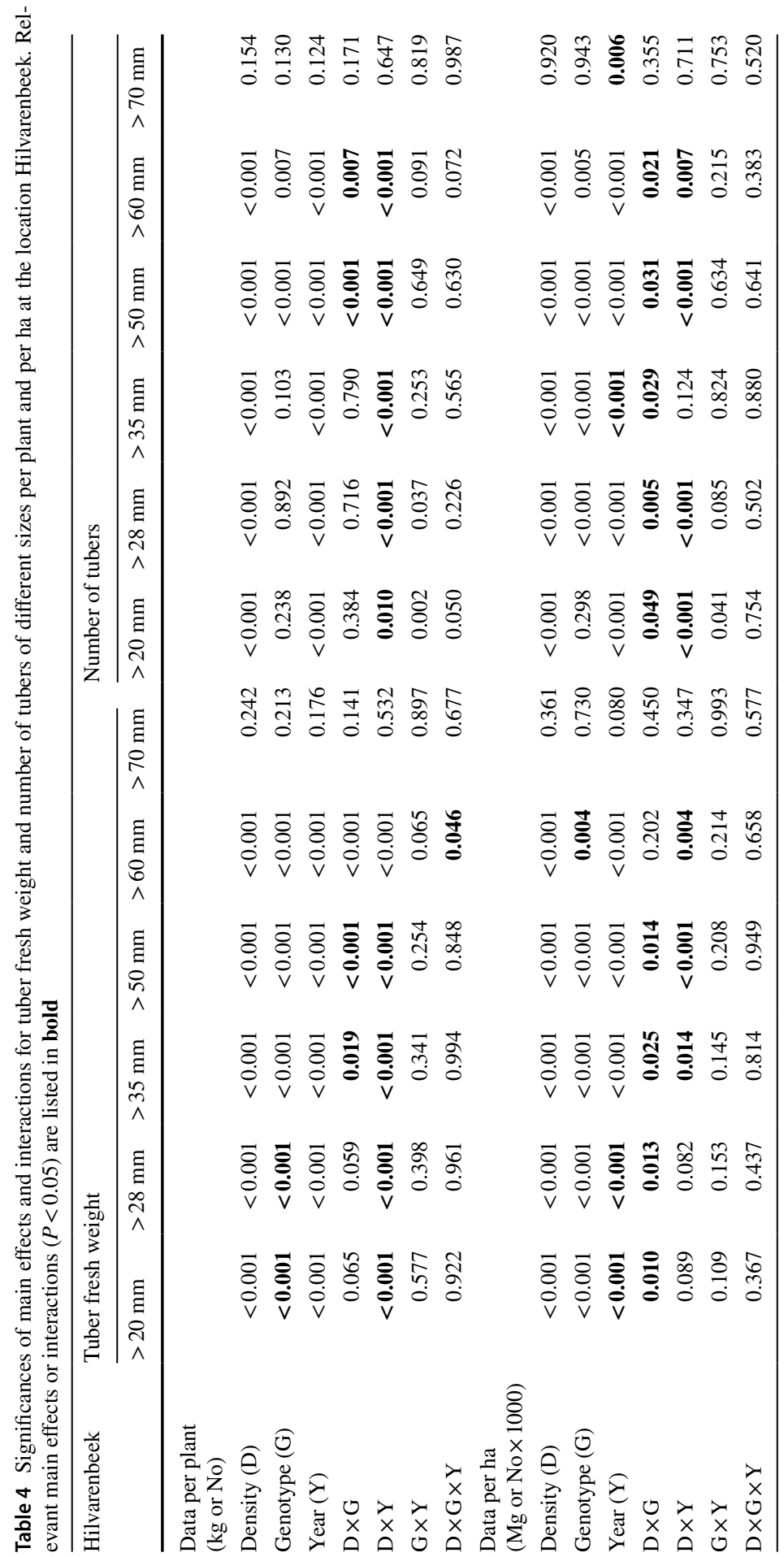



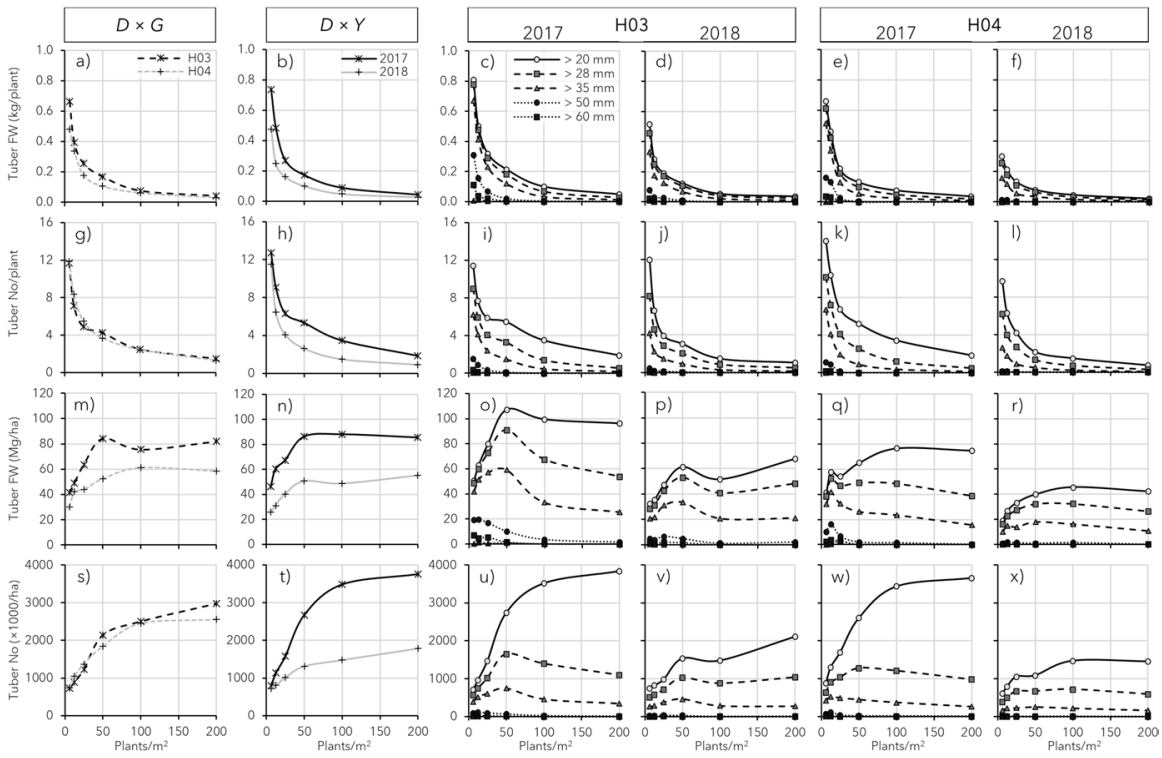

Fig. 2 Tuber fresh weight and number of tubers in different size classes per plant and per ha at Hilvarenbeek (sandy soil). From left to right graphs are shown for means of total tubers per genotype, means of total tubers per year and tuber-size thresholds for H03 2017, H03 2018, H04 2017 and H04 2018

significant anymore between 100 and 200 plants $/ \mathrm{m}^{2}$ for $\mathrm{H} 04$, but for $\mathrm{H} 03$, it still was. Likewise, the increase in number of tubers was also not significant at the highest two planting densities in 2017, but it was in 2018 .

\section{Shift in Optimum Plant Density Range with Increase in Threshold Tuber Size}

Increasing the minimum tuber-size threshold from $>20 \mathrm{~mm}$ to larger size thresholds resulted in a shift in the optimum planting densities, i.e., the planting densities where the maximum tuber yields and numbers per ha were produced. Tuber yield per ha showed significant $D \times G$ interactions for tubers $>20,>28,>35$ and $>50 \mathrm{~mm}$ (Table 4); optimal planting densities shifted for genotype $\mathrm{H} 03$ from 50-200 to 50 to $25-50$ to $6.25-25$ plants/ $\mathrm{m}^{2}$ for the above-mentioned tuber-size thresholds, respectively. The same thresholds showed in H04 a shift in optimal planting densities which ran from 50-200 to 12.5-200 to 6.25-200 to 12.5 plants $/ \mathrm{m}^{2}$, respectively (see Fig. $2 \mathrm{~m}$, o-r and Table S3 for more details).

Significant $D \times Y$ interactions regarding tuber yield per ha were observed for tuber-size thresholds $>35,>50$ and $>60 \mathrm{~mm}$ (Table 4). Optimal planting densities shifted in 2017 from $12.5-50$ to $6.25-25$ to $6.25-25$ plants $/ \mathrm{m}^{2}$ for thresholds $>35,>50$ and $>60 \mathrm{~mm}$, respectively. In 2018, the $D \times Y$ interaction showed for all these thresholds an optimum as wide as all used planting Densities (see Fig. 2n-r and Table S3). No significant differences were observed for tuber yield $>70 \mathrm{~mm}$, with tuber yields being usually $<1 \mathrm{Mg} / \mathrm{ha}$ (Tables 4 and S3).

Number of tubers per ha showed significant $D \times G$ interactions for tuber-size thresholds $>20,>28,>35,>50$ and $>60 \mathrm{~mm}$ (Table 4). From the smallest to the 
largest tuber-size threshold, optimum planting densities for $\mathrm{H} 03$ shifted from 200 to 50 to $25-50$ to $6.25-50$ to $6.25-25$ plants $/ \mathrm{m}^{2}$ and for H04 from $100-200$ to $25-100$ to $6.25-100$ to 12.5 to $6.25-12.5$ plants $/ \mathrm{m}^{2}$ (see Fig. $2 \mathrm{~s}$, $\mathrm{u}-\mathrm{x}$ and Table $\mathrm{S} 4$ for more details).

Significant $D \times Y$ interactions for number of tubers per ha were observed for tuber-size thresholds $>20,>28,>50$ and $>60 \mathrm{~mm}$ (Table 4 ). The optimum planting density shifted in 2017 from $100-200$ to 50 to 12.5 to $6.25-25$ plants $/ \mathrm{m}^{2}$ for tubersize thresholds $>20,>28,>50$ and $>60 \mathrm{~mm}$, respectively (Fig. 2t-x; Table S4). Mostly, wider ranges of optimum planting densities were observed in 2018, when the shift ran from 200 to 25-200 to 6.25-200 to 6.25-200 for the last-mentioned tuber-size thresholds. At $>70 \mathrm{~mm}$, no significant differences were observed; more than half of the Density-Genotype combinations in both Years produced less than 1000 tubers/ha $>70 \mathrm{~mm}$, which is less than 1 tuber $>70 \mathrm{~mm}$ per $10 \mathrm{~m}^{2}$ (Table S4).

\section{Effects of Planting Density in Est}

In Est, experiments were carried out on traditional potato ridges on a heavy clay soil. Plants were transplanted at 3.125, 4.6875, 6.25, 12.5, 25 and 50 plants $/ \mathrm{m}^{2}$ (Tables 1 and 2).

\section{Tuber Weight per Plant and Number of Tubers per Plant}

A significant $D \times Y$ interaction was observed for total $\mathrm{FW}$ and number of tubers (>20 mm) per plant. The $D \times G$ interaction for total number of tubers per plant was also significant (Table 5).

In both Years, an increased planting density resulted in a decrease of tuber FW per plant. At all planting densities, tuber FW per plant was higher in 2017 than in 2018. The decrease in tuber FW per plant was relatively larger in 2017 than in 2018. Tuber FW per plant decreased from 0.553 to $0.069 \mathrm{~kg}$ per plant in 2017, and from 0.246 to $0.045 \mathrm{~kg}$ per plant in 2018 (Fig. 3b; Table S5).

The $D \times Y$ and $D \times G$ interaction for total numbers of tubers per plant (Fig. $3 \mathrm{~g}-\mathrm{h}$ ) showed that an increase in planting density resulted in a decrease in number of tubers per plant. In 2017, the decrease was from 13.0 to 2.8 tubers per plant, while in 2018, plants bore about half the number of tubers of the previous year and decreased from 6.6 to 1.1 tubers per plant (Fig. 3h). The increase in planting density led to a decrease in number of tubers per plant from 7.8 to 2.0 for H03. The number of tubers per plant in genotype $\mathrm{H} 04$ decreased from 11.8 tubers per plant at 3.125 plants $/ \mathrm{m}^{2}$ to 2.0 tubers per plant at 50 plants $/ \mathrm{m}^{2}$ (Fig. $3 \mathrm{~g}$; Table S6).

An increased tuber-size class threshold from $>20 \mathrm{~mm}$ to larger sizes $(>28,>35$ and $50 \mathrm{~mm}$ ) resulted in several $D \times Y$ and $D \times G$ interactions, and the numbers of tubers $>60 \mathrm{~mm}$ showed a significant main effect of Density (Table 5). The FW and number of tubers per plant decreased with an increasing planting density (Fig. 3c-f, i-k; Tables S5 and S6). Across all Densities, FW and number of tubers per plant were higher in 2018 than in 2017. H03 produced fewer tubers $>28 \mathrm{~mm}$ per plant 


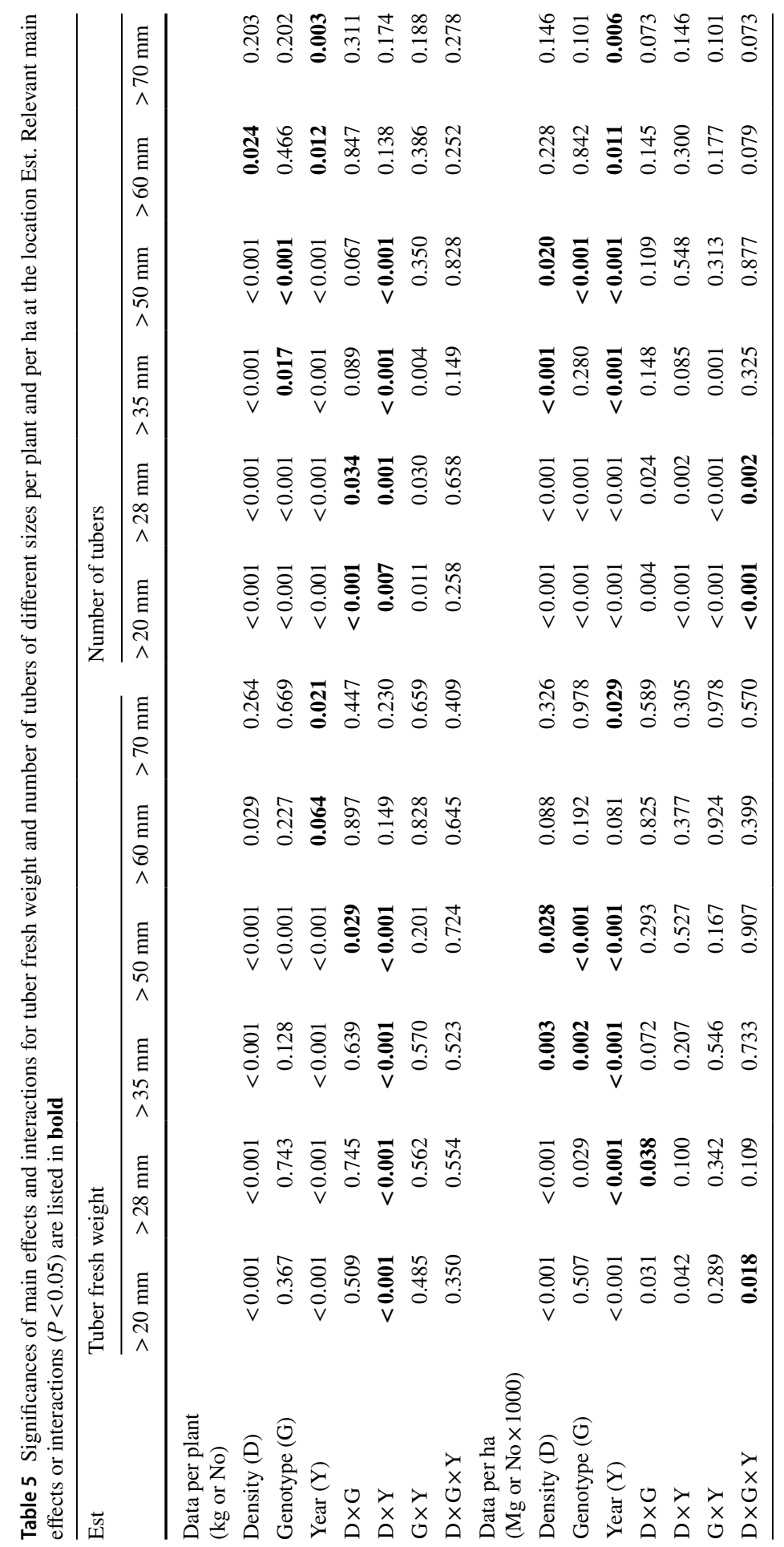



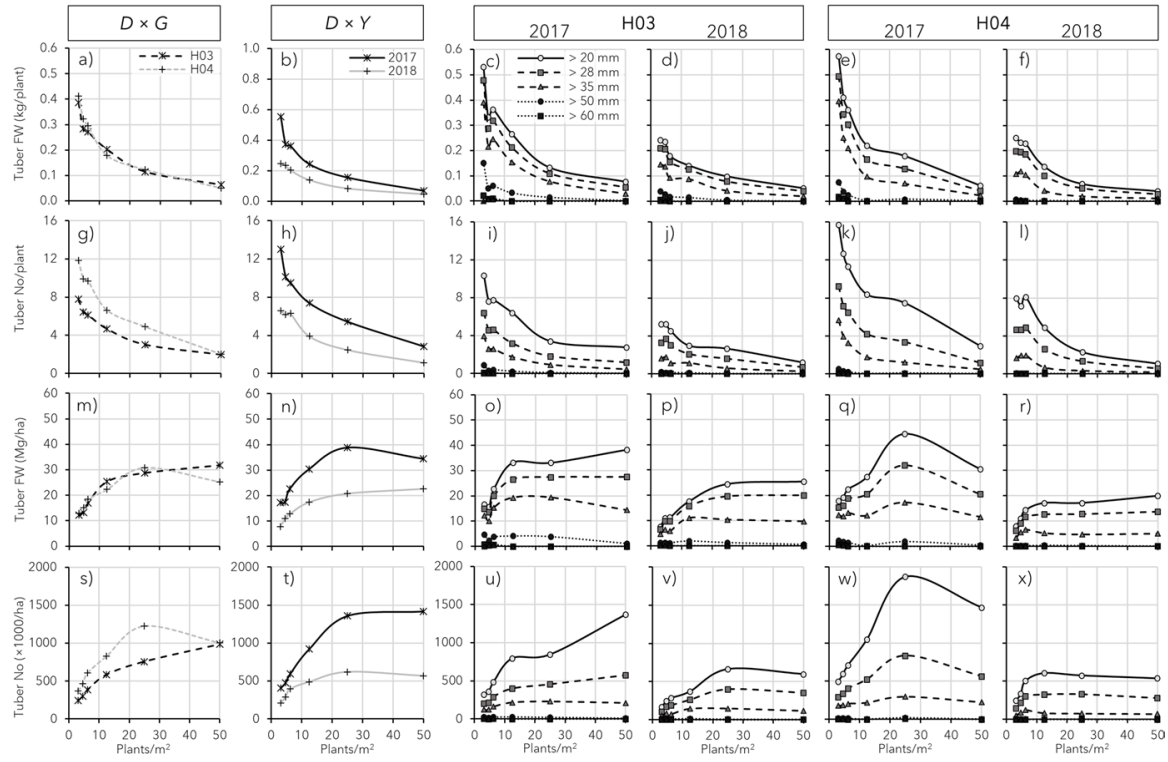

Fig. 3 Tuber fresh weight and number of tubers in different size classes per plant and per ha at Est (clay soil). From left to right graphs are shown for means of total tubers per genotype, means of total tubers per year and tuber-size thresholds for H03 2017, H03 2018, H04 2017 and H04 2018

than H04 (Fig. 3i-k; Table S6), while tubers $>50$ mm reached a higher tuber FW per plant for H03 than H04 (Fig. 3c-f; Table S5).

\section{Total Yield and Total Number of Tubers per Hectare}

For both total tuber yield and number of tubers per ha, the $D \times G \times Y$ interaction was significant (Table 5). Both parameters had their maximum when H04 was planted at 25 plants $/ \mathrm{m}^{2}$ in 2017 (45 Mg/ha, $1869 \times 10^{3}$ tubers/ha, Fig. 3q, w; Tables S7 and S8).

The maximum tuber yield of H03, 33-38 Mg/ha, was observed in 2017 at planting densities between 12.5 and 50 plants $/ \mathrm{m}^{2}$ (Fig. 3o). In 2018, the maximum yield of $\mathrm{H} 03$ was $24-25 \mathrm{Mg} /$ ha when planted at 25 and 50 plants $/ \mathrm{m}^{2}$ (Fig. 3p). The maximum yield of $\mathrm{H} 04$ was achieved at planting densities between 6.25 and 50 plants $/ \mathrm{m}^{2}$ (Fig. 3r).

\section{Shift in Optimum Plant Density Range with Increase in Threshold Tuber Size}

By increasing the minimum tuber-size threshold from $20 \mathrm{~mm}$ to larger tuber sizes, no clear optimum planting densities were observed for tuber yield or number of tubers per ha (Fig. 3m-x; Tables S7 and S8). For tuber-size thresholds $>28$ and $>35 \mathrm{~mm}$, the higher planting densities, especially 12.5 and 25 plants $/ \mathrm{m}^{2}$, were amongst the optimum. Tuber-size thresholds $>50 \mathrm{~mm}$ showed a wide range of densities which did not differ significantly from the highest value (Tables S7 and S8). 


\section{Optimum Planting Densities for Yield and Tuber Number in Commercial Size Classes}

At both Locations in both Years, tuber yields and numbers of tubers per ha were calculated for three size classes: Baby Bakers $(20<\mathrm{sc} \leq 35 \mathrm{~mm})$, Seed Tubers $(28<\mathrm{sc} \leq 50 \mathrm{~mm})$ and Large Tubers $(>50 \mathrm{~mm})$. In Hilvarenbeek, maximum tuber yields of 65, 64 and $18 \mathrm{Mg} / \mathrm{ha}$ were achieved for Baby Bakers, Seed Tubers and Large Tubers, respectively (Fig. 4c, i, o; Table S9). In Est, maximum yields were achieved of 27, 23 and $2 \mathrm{Mg} / \mathrm{ha}$ for Baby Bakers, Seed Tubers and Large Tubers, respectively (Fig. 5c, i, o; Table $\mathrm{S} 10$ ).

\section{Hilvarenbeek, Sandy Soil}

For tuber yield per ha and number of tubers per ha in the three classes in Hilvarenbeek, significant $D \times G$ and $D \times Y$ interactions were observed, except for number of tubers in the Baby Bakers class, where no significant $D \times G$ interaction was observed (Table 6).

Nevertheless, the optimum planting density (producing the maximum yield or number of tubers) for Baby Bakers was 200 plants $/ \mathrm{m}^{2}$ for both the $D$ and $G$ and $D$ and $Y$ combinations (Fig. 4a-b; Table S9).

The Seed Tuber class had its maximum yield at a planting density of 50 plants $/ \mathrm{m}^{2}$ (Fig. 4g-i; Table S9). A maximum of $81 \mathrm{Mg} / \mathrm{ha}$ Seed Tubers was produced with H03 in 2017. The optimum planting density for number of Seed Tubers per ha was also 50 plants $/ \mathrm{m}^{2}$ (Fig. 4j-1; Table S9).

The optimum planting density for Large Tubers (>50 mm) was at 12.5 plants/ $\mathrm{m}^{2}$ (Fig. 4m-r; Table S9). Genotype H03 produced a significantly higher maximum yield of $12 \mathrm{Mg} / \mathrm{ha}$ (at 6.25 and 25 plants $/ \mathrm{m}^{2}$ ) than $\mathrm{H} 04$ at $9 \mathrm{Mg} / \mathrm{ha}$ (at 12.5 plants/ $\mathrm{m}^{2}$ ) (Fig. 4m; Table S9). Significantly, the highest yield of Large Tubers in Hilvarenbeek, 15-18 Mg/ha, was recorded in 2017 at 6.25 and 12.5 plants $/ \mathrm{m}^{2}$, compared with a yield of 1-4 Mg/ha in 2018 which was recorded over the full range of Densities (Fig. 4n; Table S9).

\section{Est, Clay Soil}

Significant $D \times G \times Y$ interactions were observed for Baby Bakers yield and number of tubers per ha, and for number of Seed Tubers per ha (Table 6). Regarding yield of Seed Tubers per ha, a $D \times G$ interaction was found. Significant main effects of Density were observed for the yield and number of Large Tubers per ha.

Baby Bakers yield per ha increased with an increase in planting density up to 50 plants $/ \mathrm{m}^{2}$, except for $\mathrm{H} 04$ in 2017 , which had its optimum at 25 plants $/ \mathrm{m}^{2}$ and made the highest yield of $27 \mathrm{Mg} / \mathrm{ha}$ (Fig. 5c; Table S10). In 2018, the optimum planting density ranges (not differing significantly in yield from the highest value) were between 25 and 50 plants $/ \mathrm{m}^{2}$ for $\mathrm{H} 03$, and between 12.5 and 50 plants $/ \mathrm{m}^{2}$ for H04. The optimum planting density ranges for number of Baby Bakers tubers per ha largely followed those for Baby Bakers yield (Fig. 5f; Table S10). 
$\operatorname{Baby} \operatorname{Bakers}(>20 \leq 35 \mathrm{~mm})$
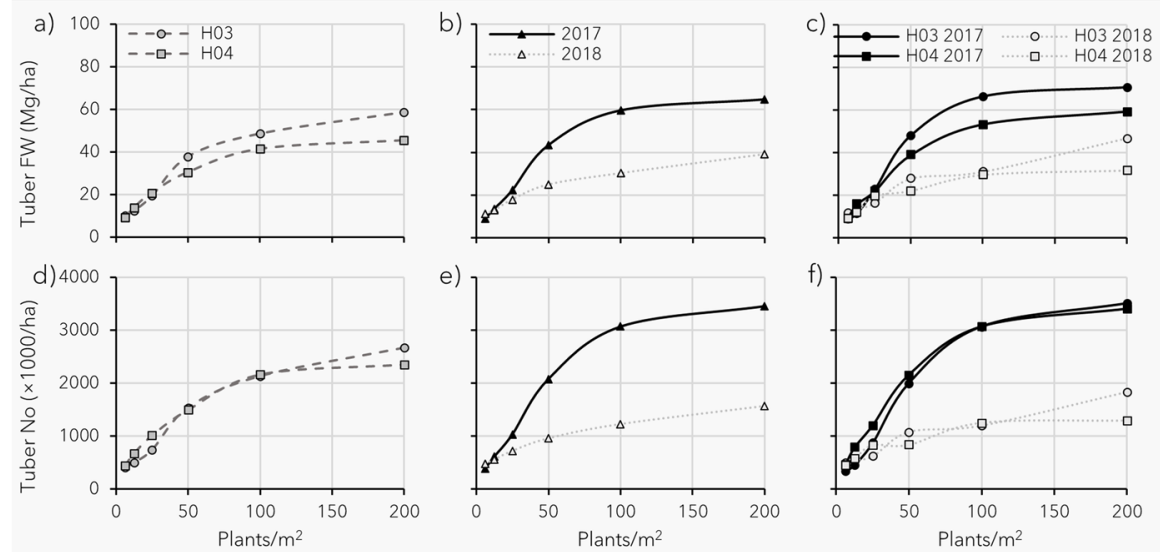

Seed Tubers ( $>28 \leq 50 \mathrm{~mm}$ )
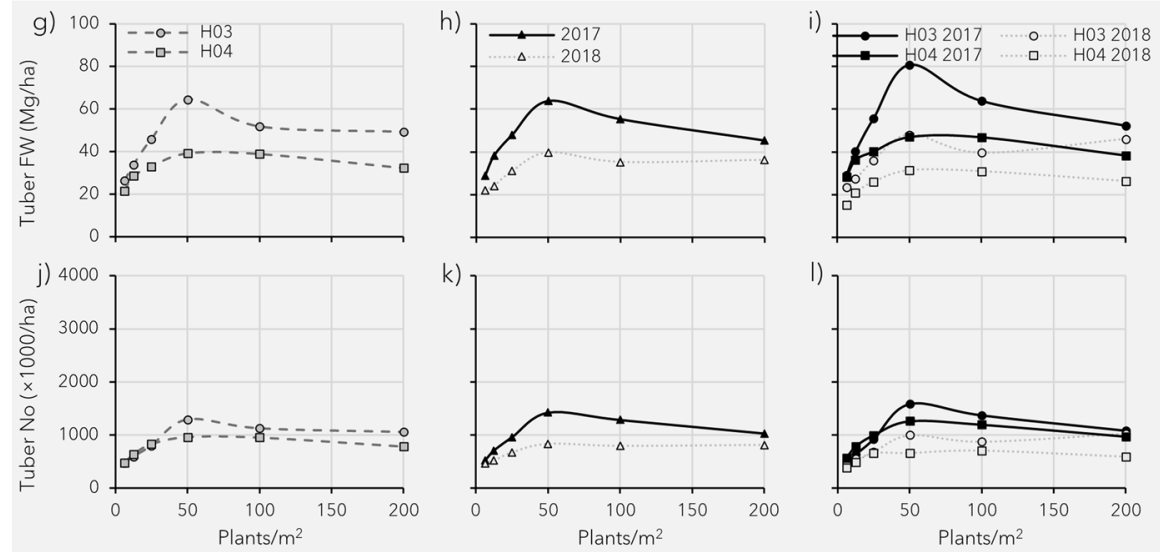

Large Tubers (>50 $\mathrm{mm}$ )
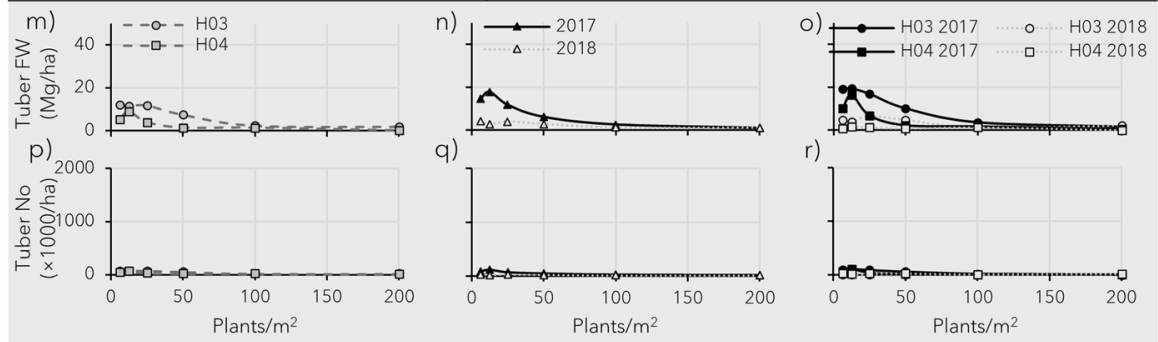

Fig. 4 Tuber fresh weight and number of tubers per ha in three commercial classes at the location Hilvarenbeek (sandy soil). Graphs from left to right show means of total tubers per genotype across years, means of total tubers per year across genotypes and means per genotype and year (H03 2017, H03 2018, H04 2017 and H04 2018). Graphs from top to bottom show Baby Bakers FW per ha, number of Baby Bakers tubers per ha, Seed Tuber FW per ha, number of Seed Tubers per ha, Large Tuber FW per ha, and number of Large Tubers per ha. For statistical analyses, see Table 6 


\section{Baby Bakers (>20 $\leq 35 \mathrm{~mm}$ )}
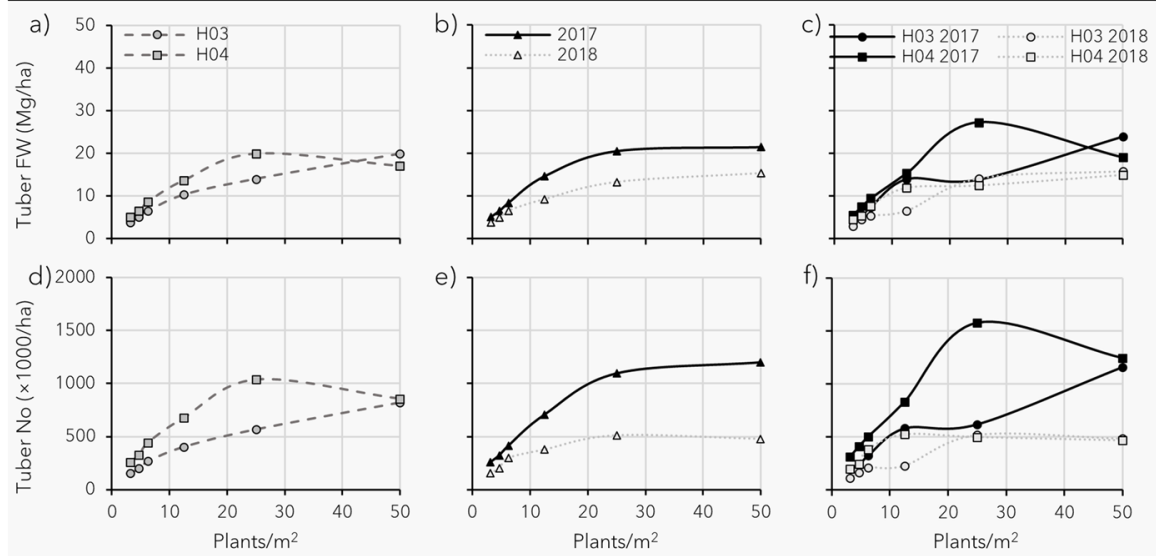

Seed Tubers ( $>28 \leq 50 \mathrm{~mm}$ )
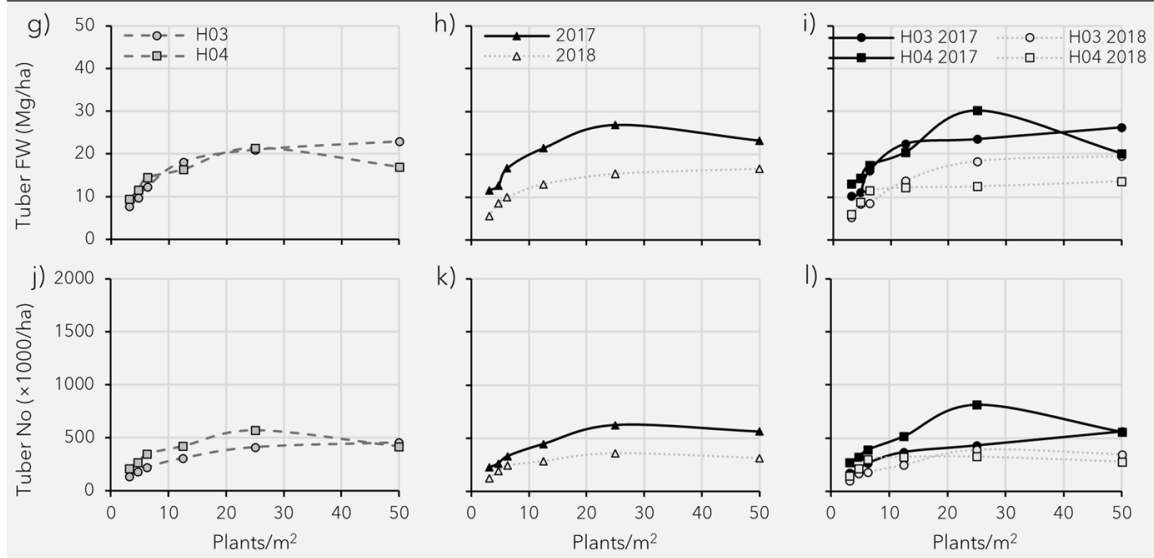

Large Tubers (>50 mm)
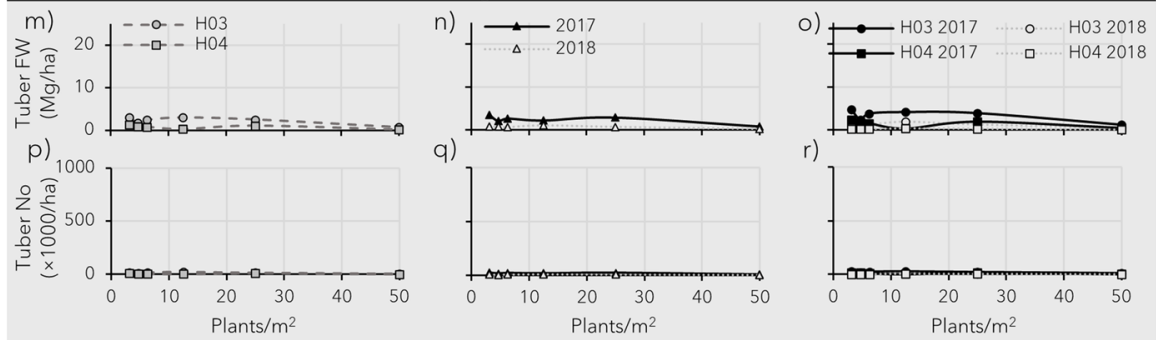

Fig. 5 Tuber fresh weight and number of tubers per ha in three commercial classes at the location Est (clay soil). Graphs from left to right show means of total tubers per genotype across years, means of total tubers per year across genotypes and means per genotype and year (H03 2017, H03 2018 , H04 2017 and H04 2018). Graphs from top to bottom show Baby Bakers FW per ha, number of Baby Bakers tubers per ha, Seed Tuber FW per ha, number of Seed Tubers per ha, Large Tuber FW per ha, and number of Large Tubers per ha. For statistical analyses, see Table 6 


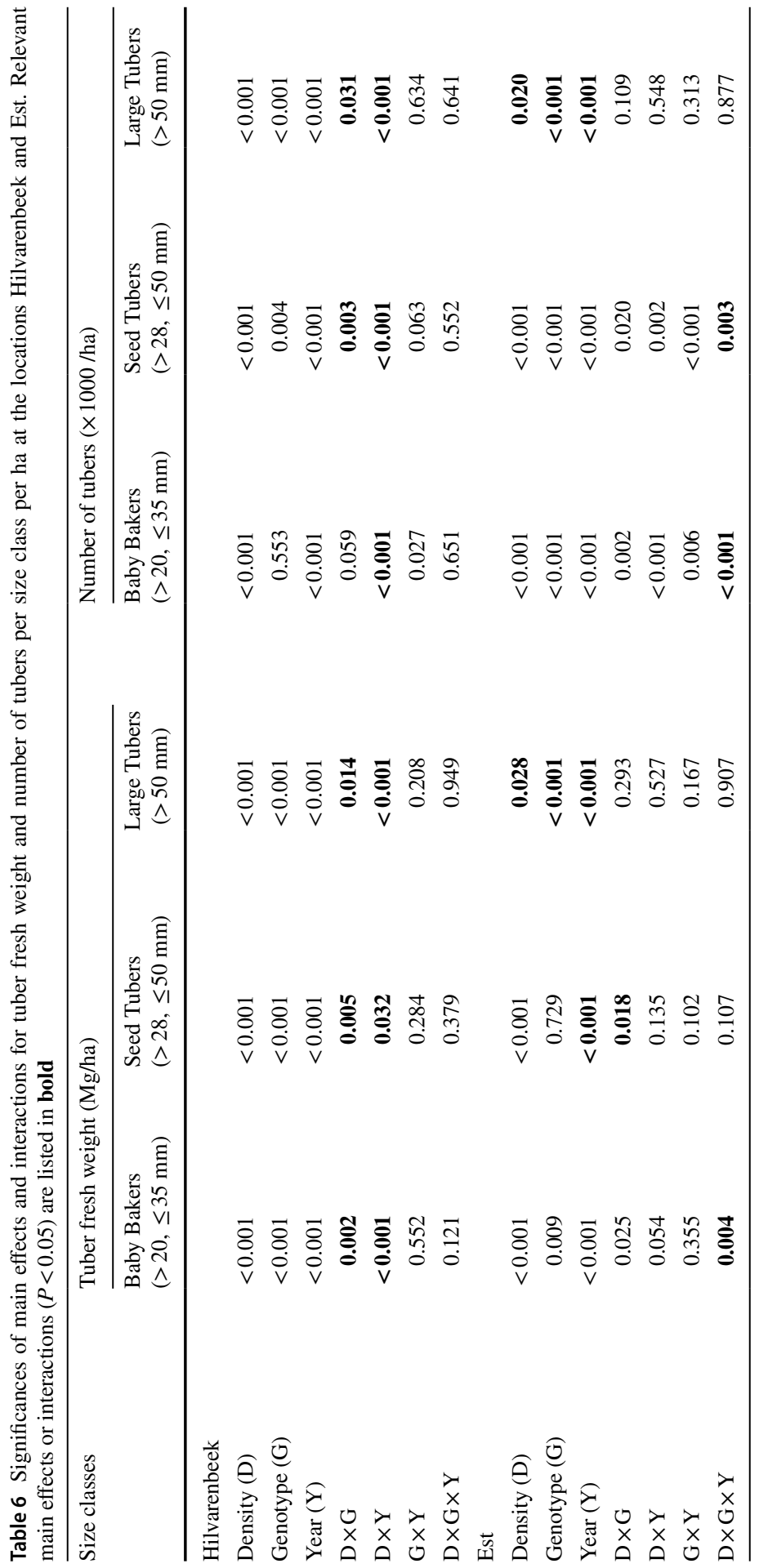


The optimum planting density for Seed Tubers in Est was 25 plants $/ \mathrm{m}^{2}$. A significantly highest yield was achieved by $\mathrm{H} 03$ at $25-50$ plants $/ \mathrm{m}^{2}$ and by $\mathrm{H} 04$ at 25 plants $/ \mathrm{m}^{2}$, producing between 21 and $23 \mathrm{Mg} / \mathrm{ha}$ (Fig. $5 \mathrm{~g}$; Table S10). The $D \times G \times Y$ interaction for number of Seed Tubers produced per ha showed similar optimum planting densities as for numbers of Baby Bakers tubers per ha (Fig. 51; Table S10).

Yield and numbers of Large Tubers per ha showed maximum values over a broad range of planting densities. For both yield and number of Large Tubers per ha, the optimum range was $3.125-25$ plants $/ \mathrm{m}^{2}$. However, at these planting densities, only 1-2 Mg/ha Large Tubers were produced (Fig. 5m-0; Table S10).

\section{Discussion}

The objectives of this study were to establish under Dutch agricultural conditions the effects of planting Density of diploid hybrid potato seedlings on tuber yield, number of tubers and tuber size, and to explore the optimum planting densities for different markets.

Planting Density was studied in two contrasting cultivation systems: (1) a flat-bed system on sandy soil located in Hilvarenbeek, and (2) a ridge system with a 75-cm row distance on a clay soil located in Est. In the flat-bed system, it was possible to use a square planting configuration, which made it possible to realise (very) high planting densities, up to 200 plants $/ \mathrm{m}^{2}$. The ridge system is the most common planting system for Dutch potato cultivation; in this system, planting densities up to 50 plants $/ \mathrm{m}^{2}$ could be realised.

When increasing planting density, total tuber yields per ha first increased to a maximum and then in most cases remained stable (Tables 2 and 3). Only in Est, did H04 in 2017 show a yield decline at densities beyond those producing the maximum yield (Fig. 3q). The flat-bed system resulted in the highest total tuber yields (76-84 Mg/ha) when H03 was planted between 50 and 200 plants $/ \mathrm{m}^{2}$. Maximum yields in the ridge system were also influenced by Year and Genotype. Planting densities between 12.5 and 50 plants $/ \mathrm{m}^{2}$ produced in general the highest total tuber yields on ridges, whereas 25 or 50 plants $/ \mathrm{m}^{2}$ were the optimum planting Density, depending on Genotype and Year.

\section{Locations, Years and Weather Conditions in Relation to Yield Maximalisation}

The optimum planting density for tuber yield maximalisation on sandy soil flat-beds was 50 plants $/ \mathrm{m}^{2}$; planting at higher densities did not significantly increase yield, but increased costs for hybrid planting materials. On traditional Dutch potato ridges on clay, the optimum planting density was between 25 and 50 plants $/ \mathrm{m}^{2}$, not very different from the more defined optimum on sandy soil flat-beds. However, maximum tuber yields achieved at these optimum densities differed considerably between Locations; on flat-beds, $107 \mathrm{Mg} / \mathrm{ha}$ was measured (Fig. 2o) while only $45 \mathrm{Mg} / \mathrm{ha}$ was made on ridges at 25 plants $/ \mathrm{m}^{2}$ (Fig. 3q), both in 2017 . The latter yield level was comparable with that of a previous study with TPS-derived plantlets, transplanted 
to an almost similar ridge system with $70 \mathrm{~cm}$ row distance, where Çalişkan et al. (2009) reported maximum total tuber yields between 47 and $53 \mathrm{Mg} / \mathrm{ha}$ at an optimum plant density ranging between 25 and 30 plants $/ \mathrm{m}^{2}$. The highest tuber yield in this study of $107 \mathrm{Mg} / \mathrm{ha}$ on sandy soil flat-beds (Fig. 2o) was in the range of the potential potato yields under Dutch conditions that were reported to be between 100 (Vos 1992) and $120 \mathrm{Mg} / \mathrm{ha}$ (Haverkort and Struik 2015).

Different factors may explain the much higher maximum yields on the flat-beds in Hilvarenbeek compared with the ridges in Est. The square design of plant spacing on the flat-beds in Hilvarenbeek made it possible to reduce competition between plants (cf. Reestman and De Wit 1959; Wiersema 1989) and might be an important factor contributing to the high yield. Combined with this, the duration of the growing period was longer in Hilvarenbeek than in Est. Plants were in the field for 160 and 163 days in 2017 and 2018, respectively, in Hilvarenbeek compared with 132 and 130 days in Est. Consequently, the total temperature sum was larger in Hilvarenbeek compared with Est in both years (Fig. 1a, c), and in 2017, the total precipitation sum during the growing period in Hilvarenbeek was almost $100 \mathrm{~mm}$ higher (130\%) compared with Est (Fig. 1b, d). Therefore, in Hilvarenbeek, plants were in the field for a longer period and accumulated more precipitation, radiation and temperature. This, combined with higher planting densities and equal spread over a square planting pattern, resulted in higher total yields, which were not limited to only the smaller tuber-size classes. Thus, effects of planting Density on tuber-size distributions were more pronounced in Hilvarenbeek than in Est where effects of planting Density on tubers in different size classes were small.

At both locations, less precipitation and larger temperature sum were recorded in 2018 than in 2017 (Fig. 1). These conditions might be the main reason for the lower mean yields and overall smaller effects of planting Density in 2018 (Figs. 2p and 3p) compared with 2017 (Figs. 2o and 3o).

\section{High Planting Densities Resulted in Lower Individual Tuber Fresh Weights}

Higher planting densities of hybrid TPS-grown plants resulted, per plant, in lower total tuber FW and fewer tubers compared with lower densities (Figs. 2a-1 and 3a-1), which is in line with previous studies not only with TPS-derived plants by Wiersema (1984) and Çalişkan et al. (2009) but also with plants derived from cuttings (Escobar and VanderZaag 1988). Also, potatoes grown from seed tubers show at the stem-level similar responses. Increased stem densities result in decreased total tuber FW and number of tubers per stem (Reestman and De Wit 1959; Wurr 1974; Allen 1978; Wiersema 1989; Struik et al. 2006; Bussan et al. 2007). For seed-tubergrown material, it is agreed that the number of stems per unit area is a better measure of density than the number of plants per unit area (Reestman and De Wit 1959; Wurr 1974; Allen 1978).

At higher stem densities, plant-available resources are more exposed to competition between stems (Allen 1978). Thus, less resources can be allocated per stem to the processes of stolon and tuber initiation and tuber bulking (Allen and Wurr 1992). Wurr (1974) suggested that at very high density, the photosynthetic capacity 
of a stem is too limited to produce enough assimilates for the tubers originating from that stem to grow into larger sizes, and thus weights.

Based on the experimental data from Hilvarenbeek and Est, Fig. 6 shows, per tested planting Density, the relationship between tuber FW and number of tubers per plant $\left(\right.$ Tuber $\left._{\mathrm{FW} / \mathrm{No}}\right)$. For all planting density-specific Tuber $_{\mathrm{FW} / \mathrm{No}}$, the depicted markers on the curve from left to right correspond with the tuber-size thresholds $>70,>60,>50,>35,>28$ and $>20 \mathrm{~mm}$. The segments between the markers in Fig. 6 correspond with the measured tuber-size classes, as explained in the "Materials and Methods" section. For example, for the top-right segment of every planting density, Tuber $_{\mathrm{FW} / \mathrm{No}}$ corresponds with the tuber-size class 20 $<\mathrm{sc} \leq 28 \mathrm{~mm}$. A steeper initial slope corresponds with a higher average FW per tuber of the largest tubers per plant, when comparing planting Densities. A steeper curve segment, and thus tuber-size class, corresponds with higher average tuber weight compared to other segments. Fig. 6 shows that low planting densities (top curves) had the highest individual tuber FW, while the lowest FW per tuber was made at high densities, as also reported by Wiersema (1984) and Çalişkan et al. (2009). Enhanced inter-tuber competition per stem at increased densities is seen as the major cause of average tuber-size reduction, and thus tuber FW per plant (Reestman and De Wit 1959; Allen and Wurr 1992).

When splitting tubers into small- $(20-28 \mathrm{~mm})$, medium- $(28-50 \mathrm{~mm})$ and largesized $(>50 \mathrm{~mm})$ tubers, Fig. 6 demonstrates that smaller tubers relatively add less to total tuber FW than to total tuber number per plant (details in Figs. S1 and S2). At a higher planting density, the absolute number of small-sized tubers decreased, but relative to the total tuber FW and number of tubers, the share of small-sized tubers did increase, at a cost of medium- and large-sized tubers. Over all planting Densities, the medium-sized tubers relatively contributed most to the total FW (Fig. 6, details Figs. S1 and S2), as also reported by Bussan et al. (2007).

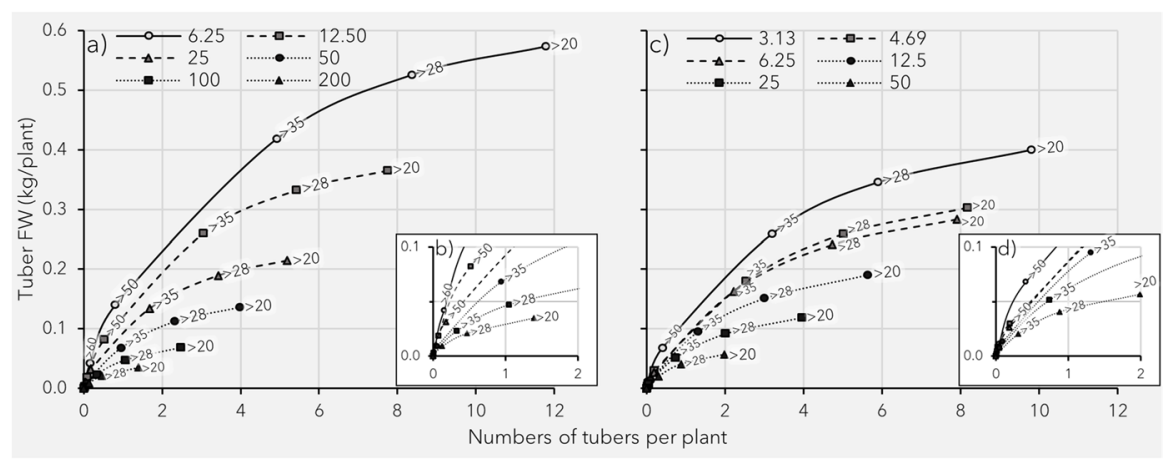

Fig. 6 Relationship between the tuber fresh weight (FW) per plant and the number of tubers per plant for studied planting densities 6.25, 12.5, 25, 50, 100, 200 plants $/ \mathrm{m}^{2}$ in Hilvarenbeek (panels a-b), and 3.125, $4.6875,6.25,12.5,25,50$ plants $/ \mathrm{m}^{2}$ in Est (panels c-d). The markers indicate the minimum size-class thresholds for a given density in panels a and $\mathbf{c}$. Panels $\mathbf{b}$ and $\mathbf{d}$ show an enlarged view of the data in the ranges up to $0.1 \mathrm{~kg} /$ plant and 2 tubers per plant 


\section{Commercial Production of Baby Bakers and Seed Tubers by Experimental Hybrid Seedlings Is Possible; Large Tubers Do Need Advanced Hybrid Genotypes}

When discriminating different commercial tuber-size classes, optimum planting densities differed between the tuber-size classes. On sandy soil flat-beds, the optimum planting density for Baby Bakers $(20<\mathrm{sc} \leq 35 \mathrm{~mm})$ was at 200 plants $/ \mathrm{m}^{2}$ while for Seed Tubers $(28<\mathrm{sc} \leq 50 \mathrm{~mm})$, this was at 50 plants $/ \mathrm{m}^{2}$, four times fewer plants compared with Baby Bakers. Aiming for maximum yields for a certain market segment might therefore lead to increased planting cost. Mean yields produced on the sandy soil with the optimal planting densities for Baby Bakers as well as Seed Tubers were high at $52 \mathrm{Mg} / \mathrm{ha}$ (Table S9).

As for total tuber yields, also for marketable yields in the commercial classes Baby Bakers and Seed Tubers, growing hybrid TPS seedlings in Est on clay ridges did produce less yield compared with the system on sandy soil flat-beds. As for total yield, a clear shift in optimum planting density from one to another commercial class was absent in Est. This differs from conventional potato production on ridges, grown from seed tubers, in which specific planting densities are used to maximise yields in different tuber target sizes (Beukema and van der Zaag 1990; Struik and Wiersema 1999; Van der Zaag 1999).

Also different from seed-tuber-grown potato production is the small share of Large Tubers ( $>50 \mathrm{~mm}$ ) produced. On sandy soil flat-beds, at an optimum planting density of around 12.5 plants $/ \mathrm{m}^{2}$, only $10 \mathrm{Mg} /$ ha were produced, $20 \%$ of the yield of the other two commercial classes. On clay soil, the Large Tubers could even be neglected as across all densities, the yield ranged between 1 and $2 \mathrm{Mg} / \mathrm{ha}$.

As explained before, the shorter growing period, and therefore less accumulated precipitation, intercepted radiation and lower temperature sum, might be a major cause of low yields on clay ridges, especially for the larger tuber-size classes. Nevertheless, the current study showed that also on sandy soil flat-beds, Large Tubers did not yield much. The experimental genotypes used in this study originated from a breeding programme which is still under development (Stockem et al. 2020). Therefore, it might be that the current genotypes lack the ability to invest available assimilates in tuber bulking rather than tuber initiation, when transplanted as greenhouse-derived seedlings into the field. TPS-grown materials are also known to have a bushier habit compared with seedtuber-grown plants, which might make tubers weaker sinks, relative to the haulm of the plants, and thus hamper tuber bulking (Wiersema 1984; Escobar and Vander Zaag 1988). More focus on the genetics which promotes tuber bulking and attenuates haulm growth might be beneficial for the development of advanced hybrids which can compete as transplanted, greenhouse-raised seedlings with seed-tuber-grown crops in conventional potato-growing systems.

\section{Further Studies}

The current study in farmers' fields showed that transplanted hybrid seedlings could have a place in the potato chain and potentially become a feasible alternative for certain potato outlets such as the commercial classes Baby Bakers and Seed Tubers. 
Further studies are needed to understand the absence of a fair share of large-sized tubers in the current hybrid material to enable access to markets which need largersized tubers. Also, fully farmer-managed trials need to assess the actual feasibility. It is suggested that more cultivar-specific trials are conducted when improved hybrid potato cultivars become available to growers. These studies will contribute with the current study, and those carried out by Kacheyo et al. (2021), Stockem et al. (2020) and van Dijk et al. (2021), useful information on the novel cultivation systems for hybrid potato, including crop management recommendations. More information will also be required on the optimal field conditions at the moment of transplanting and the subsequent seedling establishing period to enhance quick plant development.

Hybrid potatoes can be grown as transplantable vegetable for either seed(ling) tuber production or markets using small-sized tubers. When the challenge of producing also larger-sized tubers is overcome, transplants could also be used for that aim. However, the economic feasibility of raising hybrid seedlings in greenhouse nurseries and the cost of transplanting still need attention, and studies in this will help to understand if, and how many, additional seed-tuber multiplication cycles are needed from an economic point of view. Direct field sowing of hybrid potatoes might significantly reduce costs compared with a transplanted cultivation system, but has currently agronomic, plant physiological and genetic challenges regarding crop establishment, vigour and growth under field conditions.

\section{Conclusions}

The main conclusions from these first experiments of planting density of experimental diploid hybrid cultivars are:

- Increasing the planting density of diploid hybrid seedlings, derived from greenhouse nurseries, resulted in an increasing total yield.

- Tuber-size distribution was also affected with decreasing proportions of largesized tubers in favour of the small-sized tubers with increasing density.

- Medium-sized tubers remained more stable than small- or large-sized tubers when shifting densities.

- Increasing the minimum tuber-size threshold always caused a shift to lower optimum planting densities.

- Results obtained in current research showed similar trends as found in studies carried out with seed-tuber-grown materials.

On sandy soil, planted in a flat-bed system, maximum yields of commercial classes Baby Baker $(20<\mathrm{sc} \leq 35 \mathrm{~mm})$ and Seed Tuber $(28<\mathrm{sc} \leq 50 \mathrm{~mm})$ were found at 200 and 50 plants per $\mathrm{m}^{2}$, respectively. Despite high total yields on sandy soil, hybrid seedlings were unable to yield sufficiently $(10 \mathrm{Mg} / \mathrm{ha})$ in the Large Tubers $(>50 \mathrm{~mm})$ class.

On heavy clay ridges, yields were in general low and effects of planting density on tubers in different size classes were less distinctive than on sandy soil, and yields of Large Tubers were negligible. The exact causes for the absence of larger-sized tubers are unclear. 
Supplementary Information The online version contains supplementary material available at https://doi. org/10.1007/s11540-021-09522-z.

Author contribution LCMvD designed the experiments and was responsible for field trial management in consultation with MEdV. LCMvD collected and analysed the data. All authors contributed to data interpretation. The manuscript was drafted by LCMvD and revised based on input of all authors. All authors approved the final version.

Funding This study was part of the Potarei project funded by the Responsible Research and Innovation programme of the Netherlands Organisation for Scientific Research (NWO; 313-99-301). Additional funding came from Solynta, Kramp Group and Ubbo Emmius Fund.

Data availability Yes.

Code availability Not applicable.

\section{Declarations}

Ethics approval Not applicable.

Consent to participate Not applicable.

Consent for publication Yes.

Conflict of interest WJML is editor of Potato Research; PCS is editor-in-chief of Potato Research.

Open Access This article is licensed under a Creative Commons Attribution 4.0 International License, which permits use, sharing, adaptation, distribution and reproduction in any medium or format, as long as you give appropriate credit to the original author(s) and the source, provide a link to the Creative Commons licence, and indicate if changes were made. The images or other third party material in this article are included in the article's Creative Commons licence, unless indicated otherwise in a credit line to the material. If material is not included in the article's Creative Commons licence and your intended use is not permitted by statutory regulation or exceeds the permitted use, you will need to obtain permission directly from the copyright holder. To view a copy of this licence, visit http://creativecommons.org/licen ses/by/4.0/.

\section{References}

Allen EJ (1978) Plant density. In: Harris PM (ed) The potato crop. Springer, Boston. https://doi.org/10. 1007/978-1-4899-7210-1_7

Allen EJ, Wurr DCE (1992) Plant density. In: Harris PM (ed) The potato crop. Springer, Dordrecht. https://doi.org/10.1007/978-94-011-2340-2_7

Almekinders CJM, Chilver AS, Renia HM (1996) Current status of the TPS technology in the world. Potato Res 39(2):289-303. https://doi.org/10.1007/BF02360921

Beukema HP, van der Zaag DE (1990) Introduction to potato production. Pudoc, Wageningen

Blauer JM, Knowles LO, Knowles NR (2013) Manipulating stem number, tuber set and size distribution in specialty potato cultivars. Am Potato J 90(5):470-496. https://doi.org/10.1007/ s12230-013-9317-0

Bonierbale MW, Amoros WR, Salas E, de Jong W (2020) Potato breeding. In: Campos H, Ortiz O (eds) The potato crop. Springer, Cham. https://doi.org/10.1007/978-3-030-28683-5_6

Bussan AJ, Mitchell PD, Copas ME, Drilias MJ (2007) Evaluation of the effect of density on potato yield and tuber size distribution. Crop Sci 47(6):2462-2472. https://doi.org/10.2135/cropsci2007.01.0026 
Çalişkan ME, Kusman N, Çalişkan S (2009) Effects of plant density on the yield and yield components of true potato seed (TPS) hybrids in early and main crop potato production systems. Field Crops Res 114(2):223-232. https://doi.org/10.1016/j.fcr.2009.08.002

CBS (2020) CBS StatLine. Centraal Bureau voor de Statistiek, Nederland. https://opendata.cbs.nl/statl ine/. Accessed 18 March 2020

van Dijk LCM, Lommen WJM, de Vries ME, Kacheyo OC, Struik PC (2021) Hilling of transplanted seedlings from novel hybrid true potato seeds does not enhance tuber yield but can affect tuber size distribution. Potato Res 64:353-374. https://doi.org/10.1007/s11540-020-09481-x

Escobar V, VanderZaag P (1988) Field performance of potato (Solanum spp.) cuttings in the warm tropics: influence of planting system, hilling, density and pruning. Am J Potato Res 65(1):1-10. https:// doi.org/10.1007/BF02855308

Ghislain M, Douches DS (2020) The genes and genomes of the potato. In: Campos H, Ortiz O (eds) The potato crop. Springer, Cham. https://doi.org/10.1007/978-3-030-28683-5_5

Haverkort AJ, Struik PC (2015) Yield levels of potato crops: recent achievements and future prospects. Field Crops Res 182:76-85. https://doi.org/10.1016/j.fcr.2015.06.002

Jansky SH, Charkowski AO, Douches DS, Gusmini G, Richael C, Bethke PC, Spooner DM, Novy RG, De Jong H, De Jong WS, Bamberg JB, Thompson AL, Bizimungu B, Holm DG, Brown CR, Haynes KG, Sathuvalli VR, Veilleux RE, Miller C, Bradeen JM, Jiang J (2016) Reinventing potato as a diploid inbred line based crop. Crop Sci 56(4):1412-1422. https://doi.org/10.2135/cropsci2015.12. 0740

Kacheyo OC, van Dijk LCM, de Vries ME, Struik PC (2021) Augmented descriptions of growth and development stages of potato (Solanum tuberosum L.) grown from different types of planting material. Ann Appl Biol 178(3):549-566. https://doi.org/10.1111/aab.12661

Lindhout P, de Vries M, ter Maat M, Su Y, Viquez-Zamora M, van Heusden S (2018) Hybrid potato breeding for improved varieties. In: Wang-Pruski G (ed) Achieving sustainable cultivation of potatoes vol1. Burleigh \& Dodds Science Publishing, Cambridge, pp 99-123 https://doi.org/10.19103/ AS.2016.0016.04

Reestman AJ, de Wit CT (1959) Yield and size distribution of potatoes as influenced by seed rate. Neth J Agri Sci 7(4):257-268. https://doi.org/10.18174/njas.v7i4.17665

Stockem J, de Vries M, van Nieuwenhuizen E, Lindhout P, Struik PC (2020) Contribution and stability of yield components of diploid hybrid potato. Potato Res 63:345-366. https://doi.org/10.1007/ s11540-019-09444-X

Struik PC, Haverkort AJ, Vreugdenhil D, Bus CB, Dankert R (1990) Manipulation of tuber-size distribution of a potato crop. Potato Res 33(4):417-432. https://doi.org/10.1007/BF02358019

Struik PC, Wiersema SG (1999) Seed potato technology. Wageningen, Wageningen Pers

Struik PC, van der Putten PEL, Caldiz DO, Scholte K (2006) Response of stored potato seed tubers from contrasting cultivars to accumulated day-degrees. Crop Sci 46(3):1156-1168

Van der Zaag D (1999) Die gewone aardappel. Geschiedenis van de aardappel en de aardappelteelt in Nederland. Self-published, Wageningen

Vos J (1992) A case history: hundred years of potato production in Europe with special reference to the Netherlands. Am Potato J 69(11):731-751. https://doi.org/10.1007/BF02853816

Wiersema SG (1984) The production and utilization of seed tubers derived from true potato seed. University of Reading, Dissertation https://wur.on.worldcat.org/oclc/67707775

Wiersema SG (1989) Comparative performance of three small seed tuber sizes and standard size seed tubers planted at similar stem densities. Potato Res 32(1):81-89. https://doi.org/10.1007/BF023 65820

Wurr DCE (1974) Some effects of seed size and spacing on the yield and grading of two main crop potato varieties: I. Final yield and its relationship to plant population. J Agric Sci 82(1):37-45. https://doi. org/10.1017/S0021859600050206

Publisher's note Springer Nature remains neutral with regard to jurisdictional claims in published maps and institutional affiliations. 


\section{Authors and Affiliations}

Luuk C. M. van Dijk ${ }^{1,2}$ - Michiel E. de Vries ${ }^{2}$ D Willemien J. M. Lommen ${ }^{1} \mathbb{D}$. Paul C. Struik ${ }^{1}$ (D)

1 Centre for Crop Systems Analysis, Wageningen University and Research, Bornsesteeg 48, 6708 PE Wageningen, The Netherlands

2 Solynta, Dreijenlaan, 6703 HA Wageningen, The Netherlands 